\title{
Placebo Effects and the Common Cold: A Randomized Controlled Trial
}

\author{
Bruce Barrett, $M D, P b D$ \\ Roger Brown, $\mathrm{PbD}$ \\ Dave Rakel, MD \\ David Rabago, MD \\ Lucille Marchand, MD \\ Jo Scheder, $\mathrm{PbD}$ \\ Marlon Mundt, $\mathrm{PbD}$ \\ Gay Thomas, MA \\ Shari Barlow
}

University of Wisconsin, Madison, Madison, Wisconsin

Conflicts of interest: authors report none.

\section{CORRESPONDING AUTHOR}

Bruce Barrett, MD, PhD

Department of Family Medicine

University of Wisconsin-Madison

1100 Delaplaine Ct

Madison, WI 53715

bruce.barrett@fammed.wisc.edu

\begin{abstract}
PURPOSE We wanted to determine whether the severity and duration of illness caused by the common cold are influenced by randomized assignment to openlabel pills, compared with conventional double-blind allocation to active and placebo pills, compared with no pills at all.
\end{abstract}

METHODS We undertook a randomized controlled trial among a population with new-onset common cold. Study participants were allocated to 4 parallel groups: (1) those receiving no pills, (2) those blinded to placebo, (3) those blinded to echinacea, and (4) those given open-label echinacea. Primary outcomes were illness duration and area-under-the-curve global severity. Secondary outcomes included neutrophil count and interleukin 8 levels from nasal wash at intake and 2 days later.

RESULTS Of 719 randomized study participants, 2 were lost and 4 exited early. Participants were $64 \%$ female, $88 \%$ white, and aged 12 to 80 years. Mean illness duration for each group was 7.03 days for those in the no-pill group, 6.87 days for those blinded to placebo, 6.34 days for those blinded to echinacea, and 6.76 days for those in the open-label echinacea group. Mean global severity scores for the 4 groups were no pills, 286; blinded to placebo, 264; blinded to echinacea, 236; and open-label echinacea, 258. Between-group differences were not statistically significant. Comparing the no-pill with blinded to placebo groups, differences (95\% confidence interval $[\mathrm{Cl}])$ were -0.16 days $(95 \% \mathrm{Cl}$, -0.90 to 0.58 days) for illness duration and -22 severity points $(95 \% \mathrm{Cl},-70$ to 26 points) for global severity. Comparing the group blinded to echinacea with the open-label echinacea group, differences were 0.42 days $(95 \% \mathrm{Cl},-0.28$ to 1.12 days) and 22 severity points $(95 \% \mathrm{Cl},-19$ to 63 points). Median change in interleukin 8 concentration and neutrophil cell count, respectively by group, were $30 \mathrm{pg} / \mathrm{mL}$ and 1 cell for the no-pill group, $39 \mathrm{pg} / \mathrm{mL}$ and 1 cell for the group binded to placebo, $58 \mathrm{pg} / \mathrm{mL}$ and 2 cells for the group blinded to echinacea, and $70 \mathrm{pg} / \mathrm{mL}$ and 1 cell for the group with open-label echinacea, also not statistically significant. Among the 120 participants who at intake rated echinacea's effectiveness as greater than 50 on a 100-point scale for which 100 is extremely effective, illness duration was 2.58 days shorter $(95 \% \mathrm{Cl},-4.47$ to -0.68 days) in those blinded to placebo rather than no pill, and mean global severity score was $26 \%$ lower but not significantly different $(-97.0,95 \% \mathrm{Cl},-249.8$ to 55.8 points). In this subgroup, neither duration nor severity differed significantly between the group blinded to echinacea and the open-label echinacea group.

CONCLUSIONS Participants randomized to the no-pill group tended to have longer and more severe illnesses than those who received pills. For the subgroup who believed in echinacea and received pills, illnesses were substantively shorter and less severe, regardless of whether the pills contained echinacea. These findings support the general idea that beliefs and feelings about treatments may be important and perhaps should be taken into consideration when making medical decisions.

Ann Fam Med 2011;312-322. doi:10.1370/afm.1250.

\section{INTRODUCTION}

I

n 1955 Beecher, in his article "The Powerful Placebo," looked at "15 studies...involving 1,082 patients." ${ }^{11}$ Averaging results across these studies, Beecher famously claimed that "placebos are found to have 
an average significant effectiveness of $35.2 \% \pm 2.2 \%$."1 Since then, placebo effects ${ }_{1}{ }^{2-7}$ expectancy, ${ }_{1}^{8-10}$ and context effects ${ }^{11,12}$ have been studied extensively and occasionally touted as therapeutic. ${ }^{13,14}$ The evidence of placebo effects is strongest for pain ${ }^{15-20}$ and depression, ${ }^{21-24}$ where multiple well-designed trials have compared placebo with no treatment. Although the magnitude and universality of placebo effects have been questioned, ${ }^{25-27}$ blinding (concealment, masking) of matched active and placebo control groups has remained a fundamental component of clinical trials. Even so, the question of whether the results of blinded trials could be generalized to clinical practice has received little scrutiny. Few trials have included both open-label and no-treatment groups. The underlying quandary is as follows: If blinding is needed because awareness of treatment can influence outcomes, then the results of blinded trials may not generalize to real-life situations, precisely because a person is aware of his or her treatment in real life but is intentionally kept unaware in blinded trials. ${ }^{28}$

The common cold provides an excellent but underutilized opportunity to address these questions. In the United States, some 500 million noninfluenza viral respiratory infections cost society approximately $\$ 40$ billion each year. ${ }^{29} \mathrm{High}$ incidence of the common cold provides an accessible population for investigating placebo effects. Outcomes are measured in terms of symptoms, function, and impact on quality of life, all considered more responsive to placebo mechanisms than biomarkers of physiological function. Perhaps more importantly, there are no proven effective treatments for colds; hence, there are no serious ethical issues in terms of randomizing to placebo or notreatment groups.

Evidence regarding placebo effects in the common cold is limited. Eccles has reported "a review of 8 clinical trials on the effects of antitussive medicines on cough associated with acute upper respiratory tract infection [showing] that $85 \%$ of the reduction in cough is related to treatment with placebo, and only $15 \%$ attributable to the active ingredient." ${ }^{130}$ The only large common cold trial reporting placebo effects randomized 955 participants with new-onset common cold to 5 groups: no treatment, nasal saline (placebo), or 3 different doses of nasal ipratropium. ${ }^{31}$ Although the authors stressed results suggesting dose-dependent benefits of ipratropium, the difference between the placebo and no-treatment groups was greater than the difference between the placebo and any one of the active groups. In terms of nasal mucus weight, placebo beat no treatment by $27 \%(P<.01)$. Symptom severity rated on visual analogue scales was $40 \%$ lower for placebo than for no treatment $(P<.001)$. Interpretation of results is limited in that the saline nasal spray used as the placebo was not blinded, and that nasal saline may have its own physiological benefits. ${ }^{32}$

A 2002 request for applications by National Center for Complementary and Alternative Medicine at the US National Institutes of Health regarding placebo effects prompted us to propose research aimed at investigating how simulated real-life conditions (not taking a pill vs taking a named known pill) compared with conventional double-blind randomized controlled trial conditions. We chose a design that would assess 2 kinds of pill-related placebo effects (no pill vs blinded to placebo, and blinded to vs open-label treatment) and would also provide evidence regarding potential effects of physician-patient interaction. Our review of the relevant literature, ${ }^{33}$ detailed methods, ${ }^{34}$ and results related to echinacea ${ }^{35}$ and physician-patient interaction $^{36}$ are available elsewhere.

\section{METHODS}

This trial used a 2-way factorial design in which study participants with new-onset common cold were randomized in 2 directions: (1) pill-related groups, and (2) clinical interaction-related groups. Clinical interaction effects were investigated by randomization to (1) no physician visit, (2) a standard physician visit, or (3) an enhanced patient-oriented visit. A priori power estimates suggested that even if we found positive effects of both clinical interaction and pill-related interventions, we would not be able to draw firm conclusions regarding relative magnitude or possible interactions.

In the pill direction, each participant had an equal $25 \%$ chance of being randomized to 1 of 4 groups: no pill, blinded to placebo, blinded to echinacea, or open-label echinacea. Echinacea was selected as the active treatment because its popularity and name recognition provided reasonable potential of expectancyrelated placebo effects. At the time the current study was designed, several published trials of echinacea had reported benefit, ${ }^{37-40}$ whereas one, our own, ${ }^{41}$ had not. The study design reported here provided the advantage of being able to test for specific effects of echinacea in addition to the main focus on effects related to placebo and expectancy. The specific a priori hypotheses relevant to the current report were that (1) participants assigned pills would have shorter illnesses duration and lower global severity scores than those not assigned pills, (2) those getting open-label echinacea would do better than those the blinded to echinacea, and (3) those who believed in the positive effects of echinacea would do better than those who did not if they were assigned pills, especially if the pills were open-label echinacea. 


\section{Inclusion Criteria}

Participants older than 12 years were eligible if they were younger than 18 years, parental permission was obtained. To be enrolled, participants had to answer yes to either "Do you think that you have a cold?" or "Do you think you are coming down with a cold?" At least 2 points on the Jackson scale were required, with Jackson's 8 symptoms (sneezing, nasal discharge, nasal obstruction, sore throat, headache, malaise, chilliness, and cough) each rated as absent (0), mild (1), moderate (2), or severe (3). ${ }^{42}$ One of the first 4 Jackson's cold-specific symptoms was required, and none could have begun more than 36 hours before enrollment. Timing of onset of first symptom was determined by a telephone screening interview, after which the participant was interviewed in person according to a structured format. Anyone with a history of allergic rhinitis or asthma was excluded if he or she reported itchy eyes, sneezing, cough, or shortness of breath. Cold remedies other than those specified by the study protocol were disallowed. Pregnant women and those with immune system disorders were excluded.

\section{Recruitment, Enrollment, Monitoring}

We recruited participants directly from the community, using newspaper advertising, direct mailings, promotional items, and e-mail to University of Wisconsin (UW) students, staff, and alumni. Participants were enrolled at 2 sites: a UW family medicine teaching clinic in Verona, Wisconsin, and at the UW Department of Family Medicine, Madison, Wisconsin. Participants were screened by telephone, then met in person for consent, enrollment, and randomization. Nasal wash samples were obtained at enrollment, and again 2 days later. Participants completed questionnaires twice daily until their colds resolved, to a maximum of 14 days. Once colds had resolved, an exit interview was completed, and questionnaire booklets were collected.

\section{Randomization, Allocation, and Blinding}

SAS 8 (SAS Institute, Cary, North Carolina) was used to generate a single block of 804 numbers so that each of 12 cells ( 3 clinician groups by 4 pill groups) was represented equally. An envelope-within-envelope technique was used, with envelopes prepared by the UW Hospitals Pharmaceutical Research Center. Directly after consent, the larger outer envelope was opened to reveal allocation to no pill (25\%), blinded to a pill (50\%), or open-label pill (25\%). For the $66.6 \%$ of the participants randomized to a clinical visit, a second smaller envelope was opened by the clinician before entering the examination room. The randomized allocation key was not shared with investigators until after all data were collected, entered, and cleaned, and analysis strategies were determined. Blinding was tested at an exit interview by asking participants to which group they thought they had been assigned.

\section{Interventions}

Matching echinacea and placebo tablets were manufactured by MediHerb (MediHerb, Warwick, Australia). Echinacea tablets included root extracts of Echinacea purpurea and $E$ angustifolia. ${ }^{35}$ Placebo and echinacea tablets measured $9 \mathrm{~mm}$ by $19 \mathrm{~mm}$ and were covered by reddish brown digestible coatings. Investigators and colleagues found it impossible to distinguish between the placebo and echinacea pills in terms of appearance, smell, or taste. Twenty-four tablets were dispensed in conventional plastic pill bottles. Instructions were to take 2 pills 4 times in the first 24 hours, then continue with 1 pill 4 times daily for the next 4 days.

\section{Outcomes, Data Collection, and Monitoring}

Illness duration and severity were selected as primary outcomes. Duration was defined as total time elapsed from enrollment until the last time answering yes to the question, "Do you think you still have a cold?" Times and dates were recorded, so duration was measured in terms of hours and minutes, and then converted to decimalized days.

Illness severity was rated twice daily on the validated 21-item Wisconsin Upper Respiratory Symptom Survey (WURSS-21). ${ }^{43-46}$ The first and last items are assessed separately, so the total score is a simple sum of 19 items. Ten items rate cold symptoms, and 9 evaluate quality-of-life functional impairment. Each item is rated on a conventional Likert scale, in which $0=$ none, $1=$ very mild, $3=$ mild, $5=$ moderate , and $7=$ severe . Area-under-the-curve global severity was calculated by first averaging morning and evening WURSS scores, then applying trapezoidal approximations. ${ }^{47}$

Biomarkers of immune response and inflammation (interleukin 8 and neutrophil counts) were measured from nasal wash drawn at baseline (day 1) and again 2 days later (day 3). General health was assessed daily using both the 24-hour recall SF- 8 Health Survey ${ }^{48}$ and the EuroQol's Feeling Thermometer. ${ }^{49}$ The SF- 8 yields separate physical and mental health scores. ${ }^{48}$ Stress was measured with Cohen's Perceived Stress Scale-4 (PSS4), ${ }^{50,51}$ self-reported at baseline, day 3, and exit.

Belief in the effects of echinacea (expectancy) was assessed at intake by asking, "Have you ever taken echinacea before?" Participants answering yes were then asked, "How effective do you think that echinacea is?" Participants scored responses on a 100-mm visual analogue scale ranging from 0 (totally ineffective) to 100 (extremely effective).

Potential side effects were assessed with openended questions during telephone monitoring and 
again at the exit interview when we asked participants whether they had experienced any of the following during their cold: bad taste, diarrhea, headache, nausea, rash, or stomach upset.

The protocol was approved and monitored by the Human Subjects Committee of the University of Wisconsin Institutional Review Board. A committee that monitored data and safety met annually to review enrollment, retention, and adverse effects.

\section{Statistical Analysis}

The target sample size of 720 participants who would finish the protocol was based on $80 \%$ power to detect $20 \%$ differences in severity-weighted days of illness (global severity) between allocation groups, assuming $\alpha=.05$, proportionally stable standard deviation, and one-sided comparison. The decision to use one-sided testing was justified by the generally positive literature on placebo effects and was approved by multiple scientific reviewers before the trial began. Power estimates were informed by data collected during our previously published echinacea trial ${ }^{41}$ and by validation studies on the WURSS-21 instrument. ${ }^{43-46}$

The effects of assignment to placebo-related and clinician-related treatment groups were tested using analysis of variance (ANOVA), analysis of covariance, and multivariate regression. Assessment and response to missing data followed Schafer's approach. ${ }^{52}$ The final analysis structure testing for treatment effects was a general linear model ${ }^{53,54}$ implemented using NCSS statistical software. ${ }^{55}$ Models included the following covariates, all specified before data collection began: duration of symptoms before enrollment, symptom severity at enrollment, age, sex, ethnicity, education, income, smoking status, general health, and assignment to clinician intervention groups.

\section{RESULTS}

We began enrolling participants in January 2004 and concluded in August 2008. Of 3,321 persons screened, 719 were enrolled and randomized. Figure 1 shows

\section{Figure 1. Participant flowchart: entry, randomization, and follow-up of participants}

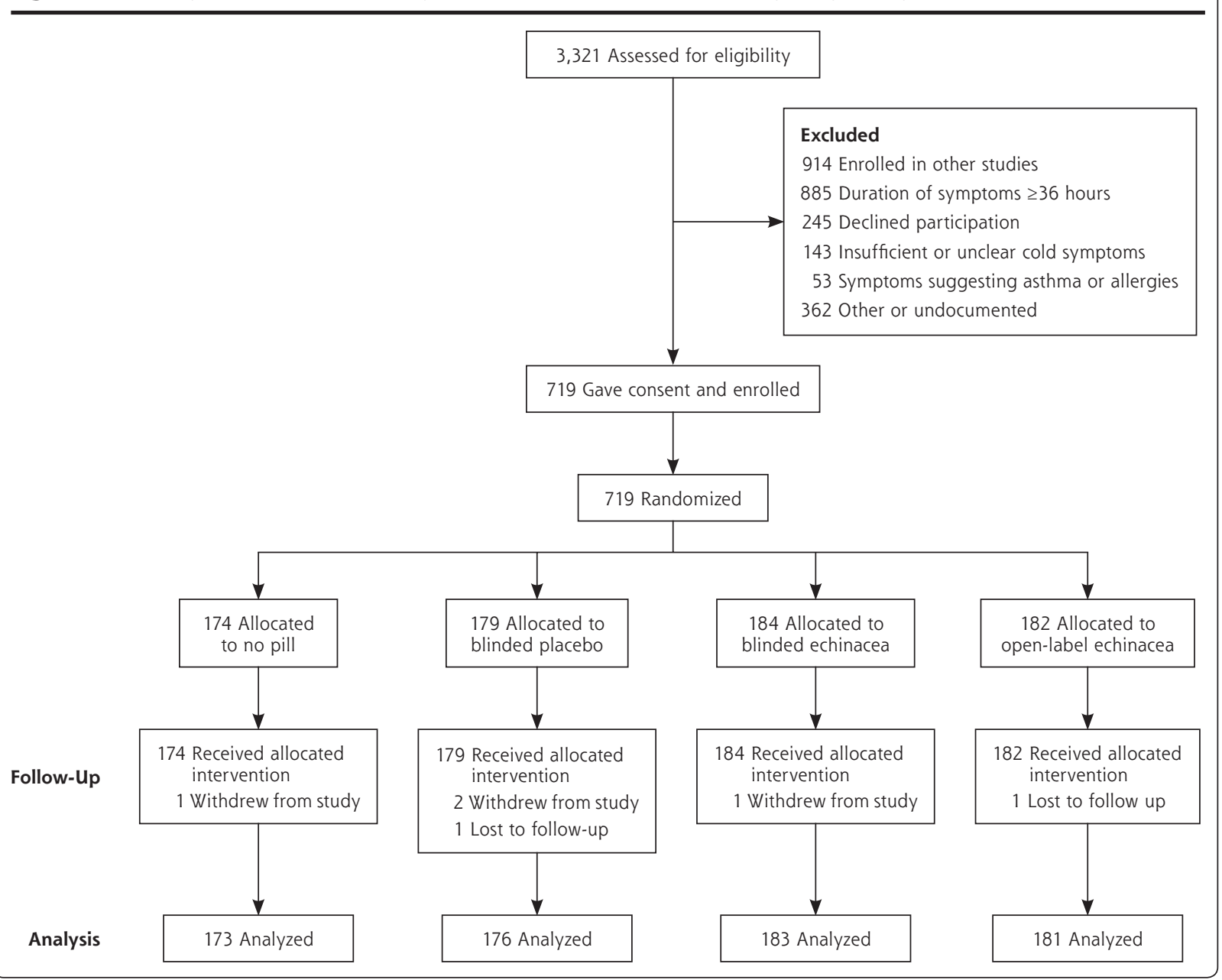


major reasons for nonenrollment. Of the 719 enrolled 2 were lost to follow-up, and 4 exited early. Duration and global severity could not be calculated for these 6 participants. Overall, there were few missing data (less than 3\%); however, 33 participants either refused or failed to show up within time limits for the nasal wash visit on day 3 , limiting sample size for interleukin 8 concentration determination and neutrophil count. Our sample was $64 \%$ female and $88 \%$ white, with $84 \%$ reporting at least some college education, and $36 \%$ reporting household incomes of $\$ 25,000$ per year or less. Only 13\% were current smokers. There were no substantive differences in the comparison groups for these baseline measures (Table 1).

As predicted, the average duration (7.03 days) and global severity scores (286 points) were greatest among those assigned to no pills (Tables 2 and 3). Compared with the no-pill group, those blinded to placebo averaged colds that were slightly shorter $(-0.16$ days; $95 \%$ $\mathrm{CI},-0.90$ to 0.58 days) and less severe ( -22 points; $95 \% \mathrm{CI},-70$ to 26$)$, differences that were not statistically significant. Comparing groups blinded to echinacea with those getting open-label echinacea, differences were 0.42 days ( $95 \% \mathrm{CI},-0.28$ to 1.12 days)
Table 1. Characteristics of Participants at Baseline, by Study Group

\begin{tabular}{|c|c|c|c|c|c|}
\hline Characteristic & $\begin{array}{c}\text { All } \\
n=719\end{array}$ & $\begin{array}{l}\text { No Pill } \\
n=174\end{array}$ & $\begin{array}{l}\text { Blinded to } \\
\text { Placebo } \\
n=179\end{array}$ & $\begin{array}{c}\text { Blinded to } \\
\text { Echinacea } \\
n=184\end{array}$ & $\begin{array}{c}\text { Open-Label } \\
\text { Echinacea } \\
n=182\end{array}$ \\
\hline Age, mean (SD), y & 33.7 (14.4) & $32.3(14.2)$ & $33.2(13.5)$ & $35.4(15.3)$ & $33.9(14.5)$ \\
\hline $\begin{array}{l}\text { Age, interquartile } \\
\text { range, y }\end{array}$ & $21.5-41.8$ & $20.8-43.4$ & $21.3-43.5$ & $21.5-46.5$ & $21.7-46.5$ \\
\hline Female, \% & 64.1 & 60.9 & 63.7 & 65.8 & 65.9 \\
\hline Nonwhite, \% & 12.1 & 13.8 & 12.3 & 14.1 & 8.2 \\
\hline Current smoker, \% & 12.8 & 14.4 & 11.2 & 14.1 & 11.6 \\
\hline $\begin{array}{l}\text { Household income } \\
\leq \$ 25,000, \%\end{array}$ & 35.9 & 40.4 & 35.7 & 35.1 & 32.6 \\
\hline $\begin{array}{l}\text { At least some } \\
\text { college, \% }\end{array}$ & 84.0 & 84.0 & 85.6 & 80.0 & 86.4 \\
\hline Belief in echinacea & [219] & [53] & {$[48]$} & [57] & [61] \\
\hline $\begin{array}{l}\text { score [No. of } \\
\text { participants], } \\
\text { mean (SD) }{ }^{\mathrm{a}}\end{array}$ & $50.3(20.6)$ & $50.7(21.4)$ & $48.2(21.5)$ & $50.7(20.5)$ & $51.4(19.4)$ \\
\hline
\end{tabular}

and 22 severity points $(95 \% \mathrm{CI}$, -19 to 63 points), with trends favoring the group blinded to echinacea. Multivariate models adjusting for potential confounders yielded nonsignificant trends toward pill benefit, with $0.35,0.62$ and 0.26 days reduced duration for the 3 pill groups compared with the nopill group. Because the global severity measure was skewed, we carried out Box Cox transformation, with or without multivariate adjustment; these analyses did not change results or conclusions.

Secondary outcomes are shown in Table 4. Changes

Table 2. Primary Outcomes: No-Pill Group vs Blinded to Placebo Group

\begin{tabular}{|c|c|c|c|}
\hline Outcome & No Pill & Blinded to Placebo & $\begin{array}{c}\text { Between-Group } \\
\text { Differences }\end{array}$ \\
\hline Sample size (protocol completers), $\mathrm{n}$ & 173 & 76 & - \\
\hline Illness duration, mean ( $95 \% \mathrm{Cl})$, d & $7.03(6.51$ to 7.56$)$ & $6.87(6.33$ to 7.41$)$ & $-0.16(-0.90$ to 0.58$)$ \\
\hline Illness duration, median $(95 \% \mathrm{Cl}), \mathrm{d}$ & $6.42(6.13$ to 7.21$)$ & 6.47 (5.82 to 7.12$)$ & $0.05(-0.78$ to 0.88$)$ \\
\hline Global severity score, mean $(95 \% \mathrm{Cl})^{\mathrm{a}}$ & 286 (249 to 323 ) & 264 (233 to 296) & $-22.0(-70.3$ to 26.3$)$ \\
\hline Global severity score, median $(95 \% \mathrm{Cl})^{\mathrm{a}}$ & 220 (189 to 238$)$ & 206 (177 to 256$)$ & $-14.0(-59.4$ to 31.3$)$ \\
\hline Transformed and adjusted global severity score $(95 \% \mathrm{Cl})^{\mathrm{b}}$ & $10.3(9.9$ to 10.7$)$ & $10.0(9.7$ to 10.4$)$ & $-0.30(-0.76$ to 0.46$)$ \\
\hline \multicolumn{4}{|l|}{ Participants who rated echinacea's effectiveness $>50^{c}$} \\
\hline Subsample size, $\mathrm{n}$ & 32 & 25 & - \\
\hline Illness duration, mean $(95 \% \mathrm{Cl})$, d & 8.41 (7.09 to 9.72$)$ & $5.83(4.44$ to 7.23$)$ & $-2.58(-4.47$ to -0.68$)$ \\
\hline Illness duration, median $(95 \% \mathrm{Cl})$, d & $7.95(6.26$ to 10.27$)$ & $4.45(4.01$ to 6.70$)$ & $-3.50(-5.80$ to -1.20$)$ \\
\hline Global severity score, mean $(95 \% \mathrm{Cl})^{a}$ & 374 (263 to 484$)$ & 277 (171 to 383$)$ & $-97.0(-249.8$ to 55.8$)$ \\
\hline Global severity score, median $(95 \% \mathrm{Cl})^{\text {a }}$ & 306 (178 to 430$)$ & 237 (115 to 330$)$ & $-69.0(-217.5$ to 79.1$)$ \\
\hline Transformed and adjusted global severity score $(95 \% \mathrm{Cl})^{b}$ & $11.3(10.0$ to 12.5$)$ & 10.2 (9.0 to 11.5$)$ & $-1.10(-2.81$ to 0.61$)$ \\
\hline \multicolumn{4}{|c|}{ SF-8 = SF-8 Health Survey; WURSS-21 = 21-item Wisconsin Upper Respiratory Symptom Survey. } \\
\hline \multicolumn{4}{|c|}{$\begin{array}{l}\text { a Global severity represents area-under-the-curve, with WURSS- } 21 \text { scores the } y \text {-axis and illness duration the x-axis. } \\
{ }^{b} \text { Because global severity was skewed, we first transformed using Box Cox methods, then adjusted for potential confounders with a mixed general linear model, } \\
\text { controlling for symptom duration before entry, cold severity at entry, age, sex, ethnicity, education, income, smoking status, physical and mental health (SF-8), and } \\
\text { randomized assignment to the } 3 \text { clinician-related groups. }\end{array}$} \\
\hline \multicolumn{4}{|c|}{$\begin{array}{l}\text { "Belief in echinacea (expectancy) was assessed by asking, "How effective do you think that echinacea is?" Participants responded by marking a visual analogue scale, } \\
\text { which ranged from } 0 \text { (totally ineffective) to } 100 \text { (extremely effective). }\end{array}$} \\
\hline
\end{tabular}


Table 3. Primary Outcomes: Blinded to Echinacea vs Open-Label Echinacea Groups

\begin{tabular}{|c|c|c|c|}
\hline Outcome & $\begin{array}{l}\text { Blinded to } \\
\text { Echinacea }\end{array}$ & $\begin{array}{l}\text { Open-Label } \\
\text { Echinacea }\end{array}$ & $\begin{array}{c}\text { Between-Group } \\
\text { Differences }\end{array}$ \\
\hline Sample size (protocol completers), $n$ & 183 & 181 & - \\
\hline Illness duration, mean $(95 \% \mathrm{Cl}), \mathrm{d}$ & 6.34 (5.86 to 6.83$)$ & $6.76(6.24$ to 7.27$)$ & $0.42(-0.28$ to 1.12$)$ \\
\hline Illness duration, median $(95 \% \mathrm{Cl}), \mathrm{d}$ & 6.04 (5.30 to 6.53$)$ & $6.16(5.31$ to 6.60$)$ & $0.12(-0.82$ to 1.05$)$ \\
\hline Global severity score, mean $(95 \% \mathrm{Cl})^{a}$ & 236 (210 to 263$)$ & 258 (226 to 289 ) & $22.0(-18.9$ to 62.9$)$ \\
\hline Global severity score, median $(95 \% \mathrm{Cl})^{\mathrm{a}}$ & 193 (163 to 218$)$ & 195 (169 to 213$)$ & $2.00(-34.0$ to 37.5$)$ \\
\hline Transformed and adjusted global severity score $(95 \% \mathrm{Cl})^{b}$ & $10.1(9.7$ to 10.4$)$ & $10.1(9.7$ to 10.5$)$ & $0.08(-0.37$ to 0.73$)$ \\
\hline \multicolumn{4}{|l|}{ Participants who rated echinacea's effectiveness $>50^{\circ}$} \\
\hline Subsample size, $\mathrm{n}$ & 33 & 30 & - \\
\hline Illness duration, mean $(95 \% \mathrm{Cl}), \mathrm{d}$ & $7.10(5.80$ to 8.40$)$ & 7.07 (5.85 to 8.29$)$ & $-0.03(-1.78$ to 1.72$)$ \\
\hline Illness duration, median $(95 \% \mathrm{Cl})$, d & $6.45(4.32$ to 8.40$)$ & 6.51 (5.50 to 8.92$)$ & $0.06(-2.46$ to 2.58$)$ \\
\hline Global severity score, mean $(95 \% \mathrm{Cl})^{\mathrm{a}}$ & 275 (179 to 370$)$ & 264 (198 to 330$)$ & $-11.0(-126.6$ to 104.6$)$ \\
\hline Global severity score, median $(95 \% \mathrm{Cl})^{\mathrm{a}}$ & 202 (125 to 264$)$ & 243 (172 to 303$)$ & $41.0(-50.2$ to 130.6$)$ \\
\hline Transformed and adjusted global severity score $(95 \% \mathrm{Cl})^{\mathrm{b}}$ & $10.1(9.1$ to 11.2$)$ & $10.4(9.5$ to 11.3$)$ & $0.30(-1.10$ to 1.70$)$ \\
\hline \multicolumn{4}{|c|}{ SF-8 = SF-8 Health Survey; WURSS-21 = 21-item Wisconsin Upper Respiratory Symptom Survey. } \\
\hline \multicolumn{4}{|c|}{$\begin{array}{l}{ }^{a} \text { Global severity represents area-under-the-curve, with WURSS- } 21 \text { scores the } y \text {-axis and illness duration the } x \text {-axis. } \\
\text { b Because global severity was skewed, we first transformed using Box Cox methods, then adjusted for potential confounders with a mixed general linear model, } \\
\text { controlling for symptom duration before entry, cold severity at entry, age, sex, ethnicity, education, income, smoking status, physical and mental health (SF-8), and } \\
\text { randomized assignment to the } 3 \text { clinician-related groups. }\end{array}$} \\
\hline \multicolumn{4}{|c|}{$\begin{array}{l}\text { 'Belief in echinacea (expectancy) was assessed by asking, "How effective do you think that echinacea is?" Participants responded by marking a visual analogue scale, } \\
\text { which ranged from } 0 \text { (totally ineffective) to } 100 \text { (extremely effective). }\end{array}$} \\
\hline
\end{tabular}

from enrollment to day 3 in neutrophil count and interleukin 8 concentration $(\mathrm{pg} / \mathrm{mL})$ were lowest in the no-pill group, and highest in the open-label echinacea group. Because interleukin 8 concentrations and neutrophil counts were highly skewed, median, geometric mean, and mean rank difference are shown instead of arithmetic mean. Figure 2 shows Cohen's $d$ standardized effect size and 95\% confidence intervals for global severity, illness duration, interleukin 8 concentration, and nasal neutrophil counts for the 3 pill groups compared with the no-pill group. Physical health, mental health, and stress were similar among the 4 groups. Four of the 6 assessed side effects were reported most frequently in the no-pill group. Headache was reported by $62 \%$ of those without pills compared with less than $50 \%$ in the other 3 groups. A $\chi^{2}$ test suggests this discrepancy is not due to chance $\left(\chi^{2}=22.3 ; P<.001\right)$. Other between-group differences of outcomes shown in Table 4 were not statistically significant.

For the 120 participants who at baseline rated echinacea's effectiveness greater than 50 on the $100-\mathrm{mm}$ expectancy scale, apparent placebo effects were more pronounced. Mean duration and global severity among the 32 participants randomly assigned no pills was 8.41 days and 374 points, compared with 5.83 days and 277 points for the participants blinded to placebo $(n=25)$, 7.10 days and 275 points for the participants blinded to echinacea ( $\mathrm{n}=33$ ), and 7.07 days and 264 points for the participants in the open-label echinacea group $(\mathrm{n}=30)$. Comparing participants with no pills with those who were blinded to placebo, illnesses were 2.58 days shorter (95\% CI, -4.47 to -0.68 days), with mean global severity 97 points (26\%) lower, but not statistically significant (-97.0 points; $95 \% \mathrm{CI},-249.8$ to 55.8 points). For this subsample of those who believed in the benefits of echinacea, those assigned placebo appeared to do as well or better than those assigned echinacea, regardless of whether they were in the group blinded to placebo or the open-label group (Tables 2 and 3). Comparing duration and global severity in the no-pill group with the other 3 groups combined (2-sample $t$ test) yielded $P=.022$ for duration and $P=.055$ for global severity. The overall $F$ test for the one-way ANOVA with 4 groups was nonsignificant for severity $(P=.30)$, but close to significant for duration $(P=.06)$.

Adherence was assessed by asking participants, "Did you take all your pills as directed?" and by pillcounts in returned bottles. Of the 545 participants given pills, $518(95 \%)$ said that they took them as directed. There were 524 bottles returned, of which $486(93 \%)$ were empty and 38 (7\%) had pills left. There were no significant differences in pill counts among those groups assigned to blinded to placebo, blinded to echinacea, and open-label echinacea.

Adequacy of blinding was tested at an exit interview by asking, "Do you believe that you were given echinacea or placebo?" Of the 363 participants blinded to which pills they were given, 141 (39\%) answered correctly, 110 (30\%) answered incorrectly, and 107 (29\%) answered "don't know" or "won't guess." Of 179 assigned placebo, 72 participants (40\%) answered correctly compared with 69 (38\%) who were blinded to 


\section{Table 4. Secondary Outcomes and Side Effects, by Study Group}

\begin{tabular}{|c|c|c|c|c|}
\hline Outcome & No Pill & $\begin{array}{l}\text { Blinded to } \\
\text { Placebo }\end{array}$ & $\begin{array}{l}\text { Blinded to } \\
\text { Echinacea }\end{array}$ & $\begin{array}{l}\text { Open-Label } \\
\text { Echinacea }\end{array}$ \\
\hline IL-8 concentration change, median, pg/mL $(95 \% \mathrm{Cl})^{\mathrm{a}}$ & $30(2-89)$ & $39(12-106)$ & $58(18-105)$ & $70(18-134)$ \\
\hline IL-8 concentration rank difference, mean, $\mathrm{pg} / \mathrm{mL}^{\mathrm{b}}$ & 322 & 333 & 330 & 358 \\
\hline $\begin{array}{l}\text { IL-8 concentration geometric change, mean, pg/mL } \\
(95 \% \mathrm{Cl})^{\mathrm{b}}\end{array}$ & $211(140-316)$ & $208(141-308)$ & $222(159-311)$ & $267(181-393)$ \\
\hline Neutrophil count change, median, $\mathrm{n}^{\mathrm{a}}$ & 1.0 & 1.0 & 2.0 & 1.0 \\
\hline Neutrophil count difference, mean rank, $n^{b}$ & 312 & 322 & 327 & 345 \\
\hline Neutrophil count, geometric change, mean $(95 \% \mathrm{CI}), \mathrm{n}^{\mathrm{b}}$ & $20.1(15-29)$ & $27.1(19-40)$ & $21.5(15-31)$ & $26.9(18-40)$ \\
\hline SF-8 physical health score, $\mathrm{n}(95 \% \mathrm{Cl})^{c}$ & $48.0(47.1-49.0)$ & $46.9(45.9-48.0)$ & $47.3(46.2-48.4)$ & $47.7(46.8-48.6)$ \\
\hline SF-8 mental health score, mean $(95 \% \mathrm{CI})^{c}$ & $43.8(42.3-45.3)$ & $42.5(41.0-43.9)$ & $44.4(43.1-45.7)$ & $43.7(42.2-45.2)$ \\
\hline EuroQol Feeling Thermometer score, mean $(95 \% \mathrm{Cl})^{c}$ & $59.0(56.0-61.9)$ & $60.8(57.5-64.0)$ & $63.1(60.3-65.9)$ & $62.0(59.2-64.8)$ \\
\hline PSS-4 stress score, mean $(95 \% \mathrm{Cl})^{c}$ & $11.7(11.2-12.1)$ & $11.4(11.0-11.9)$ & $11.5(11.1-12.0)$ & $11.5(11.1-11.9)$ \\
\hline \multicolumn{5}{|l|}{ Side effects, \% $\left(95 \%(\mathrm{Cl})^{\mathrm{d}}\right.$} \\
\hline Bad taste & NA & $9.1(7.2-16.8)$ & $12.4(7.6-17.3)$ & $8.9(4.7-13.1)$ \\
\hline Diarrhea & $5.4(2.0-8.9)$ & $12.0(7.2-16.8)$ & $9.6(5.3-13.9)$ & $9.4(5.2-13.7)$ \\
\hline Headache $^{e}$ & $62.1(54.7-69.4)$ & $49.1(41.7-56.5)$ & $46.3(39.0-53.7)$ & $47.8(40.5-55.1)$ \\
\hline Nausea & $10.2(5.6-14.9)$ & $12.6(7.7-17.5)$ & $15.8(10.4-21.2)$ & $6.7(3.0-10.3)$ \\
\hline Rash & $1.8(0.0-3.8)$ & $1.1(0.0-2.7)$ & $1.1(0.0-2.7)$ & $1.7(0.0-3.5)$ \\
\hline Stomach upset & $16.3(10.7-21.9)$ & $12.0(7.2-16.8)$ & $14.7(9.5-19.9)$ & $13.3(8.4-18.3)$ \\
\hline \multicolumn{5}{|l|}{ Participants who rated echinacea's effectiveness $>50^{f}$} \\
\hline Subsample size, $\mathrm{n}$ & 32 & 25 & 33 & 30 \\
\hline IL-8 concentration change, median, pg/mL $\left(95 \%(\mathrm{Cl})^{\mathrm{a}}\right.$ & $43(17-57)$ & $66(47-81)$ & $64(27-72)$ & $66(36-93)$ \\
\hline $\begin{array}{l}\text { IL-8 concentration geometric change, mean, } \mathrm{pg} / \mathrm{mL} \\
(95 \% \mathrm{Cl})^{\mathrm{b}}\end{array}$ & $28(18-43)$ & $55(41-75)$ & $42(29-62)$ & $56(45-70)$ \\
\hline Neutrophil count change, median, $\mathrm{n}^{\mathrm{a}}$ & $40(20-59)$ & $47(26-76)$ & $63(33-73)$ & $67(39-87)$ \\
\hline Neutrophil count, geometric change, mean $(95 \% \mathrm{CI}), \mathrm{n}^{\mathrm{b}}$ & $28(17-45)$ & $38(26-57)$ & $48(36-64)$ & $56(44-70)$ \\
\hline
\end{tabular}

IL-8 = interleukin 8; PSS-4 = Cohen's Perceived Stress Scale-4; SF-8 = SF-8 Health Survey.

${ }^{a}$ Data for IL-8 concentration and neutrophil count reflect median change in from baseline (day 1) to day 3.

${ }^{b}$ Mean rank difference and geometric mean are shown for IL-8 concentration and neutrophil count because these measures were highly skewed and did not satisfy statistical assumptions of normality.

'Mean values from day 3.

d Side effects were assessed at exit by asking whether the participant had these at any time during the cold.

e Comparing those reporting headache in the no-pill group with those in the other 3 groups combined yields $\chi^{2}$ of 22.3 , which with $1 \mathrm{df}$ is statistically significant at

$P<.001$. Using $\chi^{2}$ to test dichotomous outcomes and the $F$ test to test continuous outcomes, headache was the only between-group difference that reached $P \leq .01$.

'Belief in echinacea (expectancy) was assessed by asking, "How effective do you think that echinacea is?" Participants responded by marking a visual analogue scale,

which ranged from 0 (totally ineffective) to 100 (extremely effective).

the echinacea pills they received. These differences were not statistically significant.

\section{DISCUSSION}

Results of this trial do not support a powerful placebo effect in the common cold. The data, however, are consistent with modest placebo effects attributable to receiving pills, regardless of the content of those pills. Those who were randomly assigned pills reported illness duration that was on average 0.16 to 0.69 days shorter and $8 \%$ to $17 \%$ less severe than those assigned no pills. These observed trends were in hypothesized directions, but were not statistically significant.

Contrary to our a priori hypotheses, those who were assigned open-label echinacea did not appear to fare better than those who were blinded to echinacea. Consistent with a priori hypotheses, trends toward appar- ent placebo benefit widened among those who rated echinacea's effectiveness highly, with illnesses 1.31 to 2.58 days shorter and $26 \%$ to $29 \%$ less severe for those assigned pills compared with those assigned no pills. These differences were statistically significant for duration $(P=.022)$, but not for global severity $(P=.055)$. Among secondary outcomes, only headache seemed to be influenced by pill assignment, with $62 \%$ of those assigned no pills reporting a headache, compared with less than $50 \%$ for each of the groups assigned pills ( $P$ $<.001$ ). Because these analyses were secondary, caution should be used with interpretation.

Overall, this trial could be interpreted either as an appropriately powered trial that failed to conclusively show placebo effects, or as a trial suggesting small but perhaps meaningful effects related to expectation and pill-allocation. With respect to interpretation, at least 2 issues deserve consideration; both are crucial to 
Figure 2. Standardized effect size of pill groups compared with no-pill group.

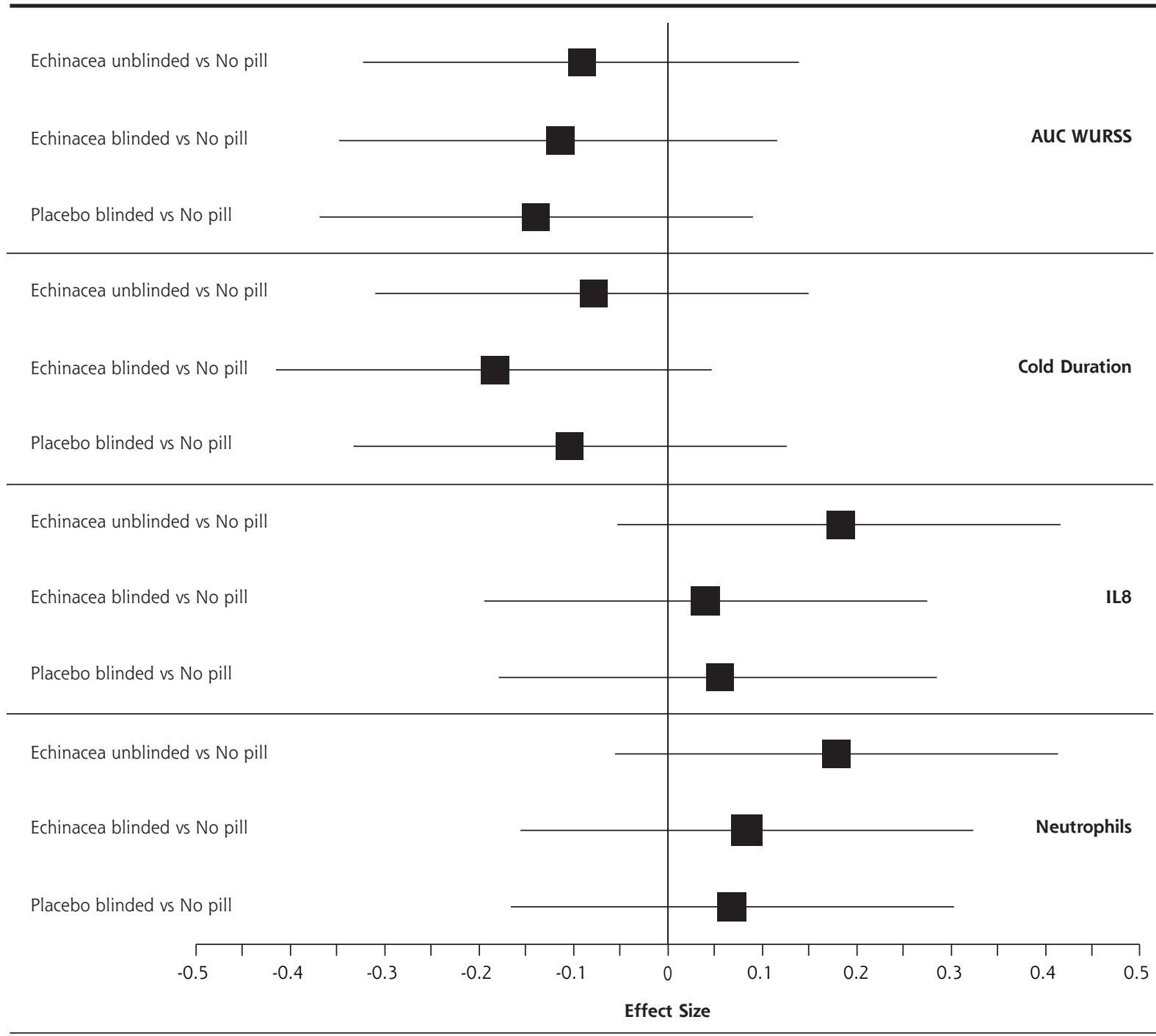

AUC = area-under-the-curve global severity; IL-8 = interleukin 8; WURSS = Wisconsin Upper Respiratory Symptom Survey.

Note: Central black boxes represent Cohen's $d$ standardized effect size; Error bars are $95 \%$ confidence intervals. These results come from a mixed general linear model adjusting for potential confounders: duration before entry, cold severity at entry, age, sex, ethnicity, education, income, smoking status, physical and mental health at entry, and assignment to the 3 clinician-related groups. Raw unadjusted results were similar.

understanding clinical trials, yet are often given inadequate attention.

The first concerns the interpretation of multiple outcomes. It is generally agreed that the statistical testing and interpretation of multiple outcomes should be undertaken with caution, as the chances of finding statistical significance increases with the number of tests done. What is not generally agreed upon is how to interpret multiple trends toward positive results when few or none of the individual tests reach significance. Some trialists have chosen to use composite endpoints, a choice that for theoretical and practical reasons is controversial. ${ }^{56,57}$ For composite endpoints to be meaningful, they should be theoretically justi- fied and specified in advance. Trials that fail to achieve statistical significance in the primary outcome but that display consistent patterns among primary and secondary outcomes are considered by some experts to be more convincing than trials that achieve statistical significance in one measure but no overall pattern. ${ }^{58,59}$ For the results displayed here, we suspect that patterns reflect real underlying causal associations, and that the trial was underpowered. Whether these possible causal associations are due to placebo mechanisms alone or whether echinacea may be contributing pharmacologically cannot be determined with the data at hand.

The second issue relates to the question of how much of a difference matters. Addressing this question, 
a minimal clinically important difference (MCID) was defined in 1989 to be "the smallest difference in score in the domain of interest which patients perceive as beneficial and which would mandate, in the absence of troubling side effects and excessive cost, a change in the patient's management. ${ }^{160}$ In 2005 we proposed the alternative concept of sufficiently important difference (SID), with SID defined as "the smallest amount of patient-valued benefit that an intervention would require in order to justify associated costs, risks, and other harms." ${ }^{161}$ Using benefit-harm trade-off structured interview methods to estimate SID for the common cold, we found that most persons would want illness duration to be reduced by at least 24 hours, ${ }^{62}$ or overall severity to be reduced by at least $30 \%,{ }^{63}$ to justify the inconvenience, cost, and possible side effects of conventional cold treatments. But average MCID or SID is only part of the story, as health values vary tremendously across patients. ${ }^{61-63}$ For low-risk interventions, such as vitamins or herbal medicine, our data suggest that more than one-quarter of the population would consider worthwhile an intervention that would reduce overall severity by $20 \%,{ }^{63}$ or the length of a cold by 12 hours, ${ }^{62}$ degrees of benefit that are well within the plausible benefit range suggested by the data shown here.

One additional issue deserves mention. In 2002, when we designed this trial, nearly all published echinacea trials had reported benefit, ${ }^{37-40}$ and societal expectations were high. Then came 4 highly publicized negative echinacea trials, our own in Annals of Internal Medicine (2002), followed by the Taylor et al trial in the Journal of the American Medical Association (2003), ${ }^{64}$ Yale and Liu's in Archives of Internal Medicine (2004), ${ }^{65}$ and the Turner et al trial in the New England Journal of Medicine (2005). ${ }^{66}$ It is possible that the societal message from these negative trials reduced echinacea-related expectancy and therefore contributed to the modest effects seen here. It is also quite possible that random assignment to no-pill or known-pill conditions poorly simulates real life, where a person is not only aware of a treatment but has actively participated in the decision to take it. The data shown here suggest that those who believe in echinacea's effectiveness may gain the most benefit from being randomly assigned to echinacea (or a pill that might be echinacea). We suspect that larger placebo effects are derived when a person chooses his or her own treatment rather than have it randomly assigned. Looking at placebo effects across a wide range of expectancies may dilute effects in participants with positive expectancy by averaging them with results of participants with neutral or even negative expectancies.

Most experts agree that placebo effects ${ }^{2-7}$ derive not from sham interventions per se, but from the beliefs, expectancies, and health-related values ${ }^{8-10}$ that are embedded in a social, cultural, and clinical context. ${ }^{11,12}$ As such, placebo effects may change with time. Perhaps the best evidence in this regard relates to depression, where most of the benefits attributable to antidepressants appear to be placebo effects, ${ }^{21-23}$ and where placebo response is "variable, substantial, and growing" over time. ${ }^{24}$ This makes sense. When antidepressants were first developed, there was a great deal of skepticism about whether pharmacologically active drugs could influence depression, long considered a problem of mental, not physical, health. As acceptance of antidepressants grew, so did the societal expectation that fuels placebo response in depression. In our case, the reverse may be true, with expectation regarding echinacea lower now than a decade ago. Speculations aside, we interpret the results reported here as suggestive of placebo effects in common cold, especially among those who believe in a therapy, but conclude that these effects are not large; instead, they are limited and nuanced.

\section{To read or post commentaries in response to this article, see it} online at http://www.annfammed.org/cgi/content/full/9/4/312.

Key words: Double-blind method; clinical trial; common cold; expectancy; placebo effect; upper respiratory tract infection

Submitted March 24, 2010; submitted, revised December 20, 2010; accepted January 18, 2011.

Funding support: The National Center for Complementary and Alternative Medicine (NCCAM) at the National Institutes of Health was primary sponsor of this research project (1-R01-AT-1428). During development of the proposal, NCCAM supported Dr Barrett with a patient-oriented career development grant (K23 AT00051). During conduct of this trial, Dr Barrett was supported by the Robert Wood Johnson Foundation Generalist Physician Faculty Scholars Program. When funds ran low before the trial had finished, leadership at the University of Wisconsin School of Medicine and Public Health provided resources to complete the project.

Acknowledgements: The Australian firm MediHerb provided the echinacea and placebo tablets used in this trial, but did not provide monetary funding, and did not review or approve this paper. Leadership at St Mary's Hospital allowed us to use their employee health clinic room for examinations and nasal wash collection. Graduate student Tola Ewers contributed to statistical analysis and table construction. The University of Wisconsin Department of Family Medicine provided invaluable institutional support. Terry Little assisted with formatting and submission. Finally, our greatest thanks go to the many research participants who volunteered their attention, energy, and good will during a time of illness.

\section{References}

1. Beecher HK. The powerful placebo. J Am Med Assoc. 1955;159(17): 1602-1606.

2. Benedetti F. Placebo Effects: Understanding the Mechanisms in Health and Disease. Oxford: Oxford University Press; 2009.

3. Finniss DG, Kaptchuk TJ, Miller F, Benedetti F. Biological, clinical, and ethical advances of placebo effects. Lancet. 2010;375(9715):686-695. 
4. Guess HA, Kleinman A, Kusek JW, Engel LW. The Science of the Placebo: Toward an Interdisciplinary Research Agenda. London: BMJ Books; 2002.

5. Harrington A. The Placebo Effect: An Interdisciplinary Exploration. Cambridge, MA: Harvard University Press; 1997.

6. Moerman DE. Meaning, Medicine and the 'Placebo Effect'. Cambridge, New York, NY: Cambridge University Press; 2002.

7. Stewart-Williams $S$, Podd J. The placebo effect: dissolving the expectancy versus conditioning debate. Psychol Bull. 2004;130(2):324-340.

8. Kirsch I, Wickless C, Moffitt KH. Expectancy and suggestibility: are the effects of environmental enhancement due to detection? Int J Clin Exp Hypn. 1999;47(1):40-45.

9. Ross M, Olson JM. An expectancy-attribution model of the effects of placebos. Psychol Rev. 1981;88(5):408-437.

10. Voudouris NJ, Peck CL, Coleman G. The role of conditioning and verbal expectancy in the placebo response. Pain. 1990;43(1):121-128.

11. Di Blasi Z, Harkness E, Ernst E, Georgiou A, Kleijnen J. Influence of context effects on health outcomes: a systematic review. Lancet. 2001;357(9258):757-762.

12. Miller FG, Kaptchuk TJ. The power of context: reconceptualizing the placebo effect. JR Soc Med. 2008;101(5):222-225.

13. Benson H, Epstein MD. The placebo effect. A neglected asset in the care of patients. JAMA. 1975;232(12):1225-1227.

14. Brody $\mathrm{H}$. Placebo response, sustained partnership, and emotional resilience in practice. J Am Board Fam Pract. 1997;10(1):72-74.

15. Benedetti F, Mayberg HS, Wager TD, Stohler CS, Zubieta JK. Neurobiological mechanisms of the placebo effect. J Neurosci. 2005;25 (45):10390-10402.

16. Hróbjartsson A, Gøtzsche PC. Is the placebo powerless? Update of a systematic review with 52 new randomized trials comparing placebo with no treatment. J Intern Med. 2004;256(2):91-100.

17. Hoffman GA, Harrington A, Fields HL. Pain and the placebo: what we have learned. Perspect Biol Med. 2005;48(2):248-265.

18. Kamper SJ, Machado LA, Herbert RD, Maher CG, McAuley JH. Trial methodology and patient characteristics did not influence the size of placebo effects on pain. J Clin Epidemiol. 2008;61(3):256-260.

19. Turner JA, Deyo RA, Loeser JD, Von Korff M, Fordyce WE. The importance of placebo effects in pain treatment and research. JAMA. 1994;271(20):1609-1614.

20. Wasan AD, Kong J, Pham LD, Kaptchuk TJ, Edwards R, Gollub RL. The impact of placebo, psychopathology, and expectations on the response to acupuncture needling in patients with chronic low back pain. J Pain. 2010;11(6)555-563.

21. Kirsch I, Moore TJ, Scoboria A, Nicholls SS. The emperor's new drugs: an analysis of antidepressant medication data submitted to the U.S. Food and Drug Administration. Prev Treat. 2002;5(23):1-12.

22. Khan A, Detke M, Khan SR, Mallinckrodt C. Placebo response and antidepressant clinical trial outcome. J Nerv Ment Dis. 2003;191(4): 211-218.

23. Moncrieff J, Wessely S, Hardy R. Active placebos versus antidepressants for depression. Cochrane Database Syst Rev. 2004;(1):CD003012.

24. Walsh BT, Seidman SN, Sysko R, Gould M. Placebo response in studies of major depression: variable, substantial, and growing. JAMA. 2002;287(14):1840-1847.

25. Hróbjartsson A, Gøtzsche PC. Is the placebo powerless? An analysis of clinical trials comparing placebo with no treatment. $N$ Engl J Med. 2001;344(21):1594-1602.

26. Hróbjartsson A, Gøtzsche PC. Placebo interventions for all clinical conditions. Cochrane Database Syst Rev. 2010;(1):CD003974.

27. Kienle GS, Kiene H. The powerful placebo effect: fact or fiction? J Clin Epidemiol. 1997;50(12):1311-1318.

28. Kaptchuk TJ. Intentional ignorance: a history of blind assessment and placebo controls in medicine. Bull Hist Med. 1998;72(3):389-433.
29. Fendrick AM, Monto AS, Nightengale B, Sarnes M. The economic burden of non-influenza-related viral respiratory tract infection in the United States. Arch Intern Med. 2003;163(4):487-494.

30. Eccles R. The powerful placebo in cough studies? Pulm Pharmacol Ther. 2002;15(3):303-308.

31. Diamond L, Dockhorn RJ, Grossman J, et al. A dose-response study of the efficacy and safety of ipratropium bromide nasal spray in the treatment of the common cold. J Allergy Clin Immunol. 1995;95(5 Pt 2):1139-1146.

32. Rabago D, Zgierska A, Mundt M, Barrett B, Bobula J, Maberry R. Efficacy of daily hypertonic saline nasal irrigation among patients with sinusitis: a randomized controlled trial. J Fam Pract. 2002;51 (12):1049-1055.

33. Barrett B, Muller D, Rakel D, Rabago D, Marchand L, Scheder JC. Placebo, meaning, and health. Perspect Biol Med. 2006;49(2):178-198.

34. Barrett B, Rakel D, Chewning B, et al. Rationale and methods for a trial assessing placebo, echinacea, and doctor-patient interaction in the common cold. Explore (NY). 2007;3(6):561-572.

35. Barrett B, Brown R, Rakel D, et al. Echinacea for treating the common cold: a randomized trial. Ann Intern Med. 2010;153(12):769-777.

36. Rakel D, Barrett B, Zhang Z, et al. Perception of empathy in the therapeutic encounter. Effects on the common cold. [Article in press]. Patient Educ Couns. 2011. doi:10.1016/j.pec.2011.01.009.

37. Dorn M, Knick E, Lewith G. Placebo-controlled double-blind study of Echinacea pallida radix in upper respiratory tract infection. Comp Ther Med. 1997;5:40-42.

38. Henneicke-von Zepelin HH, Hentschel C, Schnitker J, Kohnen R, Köhler G, Wüstenberg P. Efficacy and safety of a fixed combination phytomedicine in the treatment of the common cold (acute viral respiratory tract infection): results of a randomised, double blind, placebo controlled, multicentre study. Curr Med Res Opin. 1999; 15(3):214-227.

39. Hoheisel O, Sandberg M, Bertram S, Bulitta M, Schäfer M. Echinagard treatment shortens the course of the common cold: A doubleblind, placebo-controlled clinical trial. Eur J Clin Res. 1997;9:261-268.

40. Melchart D, Linde K, Fischer P, Kaesmayr J. Echinacea for preventing and treating the common cold. Cochrane Database Syst Rev. 2000;(2):CD000530.

41. Barrett BP, Brown RL, Locken K, Maberry R, Bobula JA, D'Alessio $D$. Treatment of the common cold with unrefined echinacea. A randomized, double-blind, placebo-controlled trial. Ann Intern Med. 2002;137(12):939-946.

42. Jackson GG, Dowling HF, Muldoon RL. Acute respiratory diseases of viral etiology. VII. Present concepts of the common cold. Am J Public Health Nations Health. 1962;52:940-945.

43. Barrett B, Brown R, Mundt M, et al. The Wisconsin Upper Respiratory Symptom Survey is responsive, reliable, and valid. J Clin Epidemiol. 2005;58(6):609-617.

44. Barrett B, Brown R, Voland R, Maberry R, Turner R. Relations among questionnaire and laboratory measures of rhinovirus infection. Eur Respir J. 2006;28(2):358-363.

45. Barrett B, Brown R, Mundt M. Comparison of anchor-based and distributional approaches in estimating important difference in common cold. Qual Life Res. 2008;17(1):75-85.

46. Barrett B, Brown RE, Mundt MP, et al. Validation of a short form Wisconsin Upper Respiratory Symptom Survey (WURSS-21). Health Qual Life Outcomes. 200;7:7.

47. Lydick E, Epstein RS, Himmelberger D, White CJ. Area under the curve: a metric for patient subjective responses in episodic diseases. Qual Life Res. 1995;4(1):41-45.

48. Ware JE, Kosinski M, Dewey JE, Gandek B. How to Score and Interpret Single-Item Health Status Measures: A Manual for Users of the SF-8 Health Survey. Lincoln, RI: QualityMetric; 2001. 
49. Revicki DA, Kawata AK, Harnam N, Chen WH, Hays RD, Cella D. Predicting EuroQol (EQ-5D) scores from the patient-reported outcomes measurement information system (PROMIS) global items and domain item banks in a United States sample. Qual Life Res. 2009; 18(6):783-791.

50. Cohen S, Tyrrell DA, Smith AP. Psychological stress and susceptibility to the common cold. N Engl J Med. 1991;325(9):606-612.

51. Cohen S, Doyle WJ, Skoner DP. Psychological stress, cytokine production, and severity of upper respiratory illness. Psychosom Med. 1999;61(2):175-180.

52. Schafer JL. Analysis of Incomplete Multivariate Data. London: Chapman \& Hall; 1997.

53. Hardin JW, Hilbe JM. Generalized Estimating Equations. Boca Raton FL: Chapman \& Hall / CRC; 2003.

54. Mardia KV, Kent JT, Bibby JM. Multivariate Analysis. New York: Academic Press; 1979.

55. Hintze J. NCSS Statistical Package. Kaysville, Utah: NCSS, LLC (http:// www.ncss.com), 2007.

56. Borm GF, Teerenstra S, Zielhuis GA. Objective and perspective determine the choice of composite endpoint. J Clin Epidemiol. 2008; 61(2):99-101.

57. Cordoba G, Schwartz L, Woloshin S, Bae H, Gøtzsche PC. Definition, reporting, and interpretation of composite outcomes in clinical trials: systematic review. BMJ. 2010;341:c3920.

58. Pocock SJ, Geller NL, Tsiatis AA. The analysis of multiple endpoints in clinical trials. Biometrics. 1987;43(3):487-498.
59. Stang A, Poole C, Kuss O. The ongoing tyranny of statistical significance testing in biomedical research. Eur J Epidemiol. 2010;25(4): 225-230.

60. Jaeschke R, Singer J, Guyatt GH. Measurement of health status. Ascertaining the minimal clinically important difference. Control Clin Trials. 1989;10(4):407-415.

61. Barrett B, Brown D, Mundt M, Brown R. Sufficiently important difference: expanding the framework of clinical significance. Med Decis Making. 2005;25(3):250-261.

62. Barrett B, Brown R, Mundt M, et al. Using benefit harm tradeoffs to estimate sufficiently important difference: the case of the common cold. Med Decis Making. 2005;25(1):47-55.

63. Barrett B, Harahan B, Brown D, Zhang Z, Brown R. Sufficiently important difference for common cold: severity reduction. Ann Fam Med. 2007;5(3):216-223.

64. Taylor JA, Weber W, Standish L, et al. Efficacy and safety of echinacea in treating upper respiratory tract infections in children: a randomized controlled trial. JAMA. 2003;290(21):2824-2830.

65. Yale SH, Liu K. Echinacea purpurea therapy for the treatment of the common cold: a randomized, double-blind, placebo-controlled clinical trial. Arch Intern Med. 2004;164(11):1237-1241.

66. Turner RB, Bauer R, Woelkart K, Hulsey TC, Gangemi JD. An evaluation of Echinacea angustifolia in experimental rhinovirus infections. N Engl J Med. 2005;353(4):341-348.

\section{CHANGE-OF-ADDRESS FORM FAMNILY MEDICINE}

Please complete this form and mail to the following address or fax to Annals Circulation at 913-906-6080:

Annals of Family Medicine, Circulation Department, 11400 Tomahawk Creek Pkwy, Leawood, KS 66211-2680

Check if member of sponsoring organization: $\square$ AAFP $\quad \square$ ABFM $\quad \square$ STFM $\square$ ADFM

\section{$\square \mathrm{AFMRD} \square \mathrm{NAPCRG} \square \mathrm{CFPC}$}

ID number from label on your journal cover

OLD Information (Please print.)

\section{Name}

Company (if applicable)

Address (Street plus Apt or Ste)

\begin{tabular}{ll}
\hline City & State \\
\hline Country & Postal Code (9-digit ZIP for US) \\
\hline Telephone & Fax \\
\hline E-Mail &
\end{tabular}

NEW Information (Please print.)

\begin{tabular}{ll}
\hline Name \\
\hline Company (if applicable) \\
\hline Address (Street plus Apt or Ste) \\
\hline City & Postal Code (9-digit ZIP for US) \\
\hline Country & \\
\hline Telephone & \\
\hline E-Mail &
\end{tabular}

